\title{
Polythiophene-Chitosan Magnetic Nanocomposite as a Highly Efficient Medium for Isolation of Fluoxetine from Aqueous and Biological Samples
}

\author{
Alireza Feizbakhsh, Amir Hossein Mohsen Sarrafi, and Shokooh Ehteshami \\ Analytical Chemistry Laboratories, Department of Chemistry, Islamic Azad University, Central Tehran Branch, Tehran, Iran \\ Correspondence should be addressed to Alireza Feizbakhsh; ali.fb1973@yahoo.com
}

Received 7 February 2016; Revised 18 April 2016; Accepted 3 July 2016

Academic Editor: Yolanda Moliner Martínez

Copyright (C) 2016 Alireza Feizbakhsh et al. This is an open access article distributed under the Creative Commons Attribution License, which permits unrestricted use, distribution, and reproduction in any medium, provided the original work is properly cited.

Polythiophene/chitosan magnetic nanocomposite as an adsorbent of magnetic solid phase extraction was proposed for the isolation of fluoxetine in aqueous and biological samples prior to fluorescence detection at $246 \mathrm{~nm}$. The synthesized nanoparticles, chitosan and polythiophene magnetic nanocomposite, were characterized by scanning electron microscopy, FT-IR, TGA, and EDAX. The separation of the target analyte from the aqueous solution containing the fluoxetine and polythiophene/chitosan magnetic nanocomposite was simply achieved by applying external magnetic field. The main factors affecting the extraction efficiency including desorption conditions, extraction time, ionic strength, and sample solution $\mathrm{pH}$ were optimized. The optimum extraction conditions were obtained as $10 \mathrm{~min}$ for extraction time, $25 \mathrm{mg}$ for sorbent amount, $50 \mathrm{~mL}$ for initial sample volume, methanol as desorption solvent, $1.5 \mathrm{~mL}$ for desorption solvent volume, $3 \mathrm{~min}$ for desorption time, and being without salt addition. Under the optimum conditions, good linearity was obtained within the range of $15-1000 \mu \mathrm{g} \mathrm{L}^{-1}$ for fluoxetine, with correlation coefficients 0.9994. Furthermore, the method was successfully applied to the determination of fluoxetine in urine and human blood plasma samples. Compared with other methods, the current method is characterized with highly easy, fast separation and low detection limits.

\section{Introduction}

One of the most common serotonin specific reuptake inhibitors in neurons of presynaptic is N-methyl-3-phenyl-3[4-(trifluoromethyl)phenoxy]propylamine hydrochloride or fluoxetine hydrochloride (Figure 1). It was developed since the late 1980s and is the most significant category of antidepressant drugs globally. Recently, fluoxetine was applied in the obsessive-compulsive treatment and eating disorders such as bulimia nervosa and anorexia. The acid dissociation constant $\left(\mathrm{p} K_{\mathrm{a}}\right.$ ) of fluoxetine is 8.7 as well as having $\log K_{\text {ow }}$ of $1.0,1.8$, and 2.6 ( $\mathrm{pH}$ values 5, 7, and 9) [1-3]. Elimination halflife of fluoxetine was ranged from one to several days, and less than $11 \%$ excreted unchanged fluoxetine while it is mainly excreted in urine [4]. A lot of fluoxetine rejection occurs in urine along with small amounts in the feces [5]. The dose of therapeutic could change from 20 to $60 \mathrm{mg}$ per day related to the treatment and the levels of excreted urine are generally at $\mathrm{mg} \mathrm{L}^{-1}$ [4]. In sight of the above considerations, the improvement of separation method for the fluoxetine determination from urine sample could be applied for toxicological and therapeutic purposes. Temporarily, due to high consumption of fluoxetine, a spreading threat of few residuals can occur into the environmental waters. The fluoxetine determination in biological samples is rather vital in human pharmacokinetic analysis, in drug's therapeutic checking, and in bioavailability/bioequivalence studies [1-4], while determination of fluoxetine in environmental water sample remains a drastic challenge in health issues. Diverse techniques have been applied for preconcentration and determination of trace amounts of fluoxetine in both aqueous and biological fluid phase samples. Different sample preparation methods such as liquid-liquid extraction $[3,6]$, solid phase extraction (SPE) [7], and stir bar sorptive extraction (SBSE) [8] along with 
<smiles>CNCCC(Oc1ccc(C(F)(F)F)cc1)c1ccccc1</smiles>

FIgURE 1: Structure of fluoxetine hydrochloric.

chromatographic [3-9], spectrofluorimetric [3, 6, 10], and spectrophotometric instrument $[6,11]$ have been applied for determination of fluoxetine from biological and aqueous samples.

Although SPE technique was extensively used for various matrices, it has several drawbacks such as being timeconsuming and tedious, needing too much organic solvents, and being relatively expensive. Lately, considerable attempts have been performed to develop new techniques to overcome these disadvantages. A new sample preparation derived of SPE is magnetic solid phase extraction that uses magnetic nanoparticles as adsorbents [12]. In this method, the sorbent does not demand to be filled into the SPE column; instead of it, the magnetic adsorbents are directly dispersed in the sample solution. Since the efficiency of extraction is enhanced because the contact interface between sorbents and analytes was increased, separation of phase can be easily performed from liquid phase to use an external magnetic field. Therefore, the magnetic sorbent can be quickly separated by a magnet and avoids the tedious centrifugation or filtration procedure [13-15].

These advantages of MSPE have caused that its applications in various fields, for instance, bioseparation, were increased [16-20]. However, the unmodified magnetic nanoparticles due to electrostatic and dipole-dipole interactions are easily accumulated and the surface area of particles was severely decreased. Therefore, the modification of their surface can not only enhance stability of magnetic particles in sample matrix but also offer a specific surface to interact with certain molecules such as organic and inorganic compounds [21, 22]. To date, several types of material such as organic polymers and inorganic materials have been used for alteration of reactivity of the magnetic nanoparticles. Among these modifiers, functional alkyl groups [23-25], organic polymers [26-29], graphene and graphene oxide [30-32], carbon nanotubes [33], and surfactants [34-36] are commonly investigated. Recently, conducting polymers (CPs) have been widely used as new coating materials [37, 38]. Polythiophene (PTh) compared to other CPs including polyaniline and polypyrrole has gained great attention because it is more stable than the others in high temperature and various solvents [39-41]. Yamini [40, 41] introduced a new MSPE sorbent based on PTh-coated $\mathrm{Fe}_{3} \mathrm{O}_{4} \cdot \mathrm{Fe}_{3} \mathrm{O}_{4}$ nanoparticles do not have organic functional groups that can affect their adsorptive properties [42]. To overcome these limitations and increase the prominent merits of the magnetic materials, in this work, chitosan can be applied as a new modifier with the low aggregation properties during the growth of $\mathrm{Fe}_{3} \mathrm{O}_{4}$ nanoparticles.
Therefore, chitosan can act not only as a "support" for the growth of $\mathrm{Fe}_{3} \mathrm{O}_{4}$ nanoparticles, but also as a "spacer" for the inhibition of nanoparticles aggregation.

For the first time, we developed polythiophene/chitosan magnetic nanocomposite as the MSPE technique for the extraction and analysis of fluoxetine in aqueous and biological sample. Firstly, magnetic nanoparticles and chitosan magnetic were synthesized through a facile coprecipitation, while different types of magnetic nanocomposites with different concentrations of thiophene $(0.03-2 \mathrm{M})$ were coated on the surface of chitosan $/ \mathrm{Fe}_{3} \mathrm{O}_{4} \mathrm{NPs}$ by oxidized polymerization. The capability of these sorbents for extracting fluoxetine was examined. Extraction and desorption conditions were also optimized. To demonstrate the validation of the proposed method, the quantification limit, linearity, and precision were investigated.

\section{Experimental}

2.1. Reagents. Fluoxetine hydrochloride (99.37\%) was obtained from Dr. Reddy Company (India). The fluoxetine standard solution (2000 $\left.\mathrm{mg} \mathrm{L}^{-1}\right)$ was prepared with methanol (HPLC-grade) and stored at $2^{\circ} \mathrm{C}$ in refrigerator. Then, the working solution that contains concentrations was daily prepared via diluting the standard solution with double distilled water. Other chemicals such as sodium chloride, $\mathrm{FeCl}_{3} \cdot 6 \mathrm{H}_{2} \mathrm{O}, \mathrm{FeCl}_{2} \cdot 4 \mathrm{H}_{2} \mathrm{O}$, hydrochloric acid, sodium hydroxide, and methanol, ethanol, chloroform, dichloromethane, acetonitrile, and acetic acid were of analytical grades and were purchased from Merck (Darmstadt, Germany). The nitrogen gas (99.99\%) was applied for providing the inert atmosphere necessary for synthesis of nanoparticles (NPs) and their coating process. Also, ammonium peroxydisulfate (APS) was obtained from Merck (Darmstadt, Germany) and was used without further treatment while thiophene (Mississauga, Canada) was distilled under reduced pressure.

2.2. Preparation of Magnetic $\mathrm{Fe}_{3} \mathrm{O}_{4}$ Nanoparticles. $\mathrm{Fe}_{3} \mathrm{O}_{4} \mathrm{NPs}$ were prepared by coprecipitation of $\mathrm{FeCl}_{3}$ and $\mathrm{FeCl}_{2}$ [46]. Typically, $250 \mathrm{~mL}$ of sodium hydroxide solution with concentration of $1.5 \mathrm{M}$ was prepared in ultrapure water under inert atmosphere at $\mathrm{N}_{2}$ gas. Then, an iron solution containing $5.2 \mathrm{~g}$ of $\mathrm{FeCl}_{3} \cdot 6 \mathrm{H}_{2} \mathrm{O}$ and $2.0 \mathrm{~g}$ of $\mathrm{FeCl}_{2} \cdot 4 \mathrm{H}_{2} \mathrm{O}$ as well as $0.85 \mathrm{~mL}$ of concentrated hydrochloric acid was freshly prepared in $25 \mathrm{~mL}$ of ultrapure water under inert atmosphere at $\mathrm{N}_{2}$ gas. Finally, the iron solution was added dropwise to the sodium hydroxide solution during $60 \mathrm{~min}$ with maximum vigorous stirring under a nitrogen atmosphere. The resulting black precipitates were separated from the reaction medium by a $1.4 \mathrm{~T}$ magnet and washed several times with degassed ultrapure.

2.3. Preparation of Chitosan-Coated Magnetic Nanoparticles. The chitosan magnetic nanoparticles (CS/MNPs) were prepared according to the following process. Firstly, $100 \mathrm{~mL}$ acetic acid aqueous solution $(0.5 \% \mathrm{v} / \mathrm{v})$ containing $5 \mathrm{~g} \mathrm{~L}^{-1} \mathrm{CS}$ and $\mathrm{FeCl}_{3} \cdot 6 \mathrm{H}_{2} \mathrm{O}(9.22 \mathrm{~g})$ as well as $\mathrm{FeCl}_{2} \cdot 4 \mathrm{H}_{2} \mathrm{O}(3.2 \mathrm{~g})$ was freshly synthesized with maximum vigorous stirring at $45^{\circ} \mathrm{C}$ under the nitrogen atmosphere for $30 \mathrm{~min}$. Then, the solution 


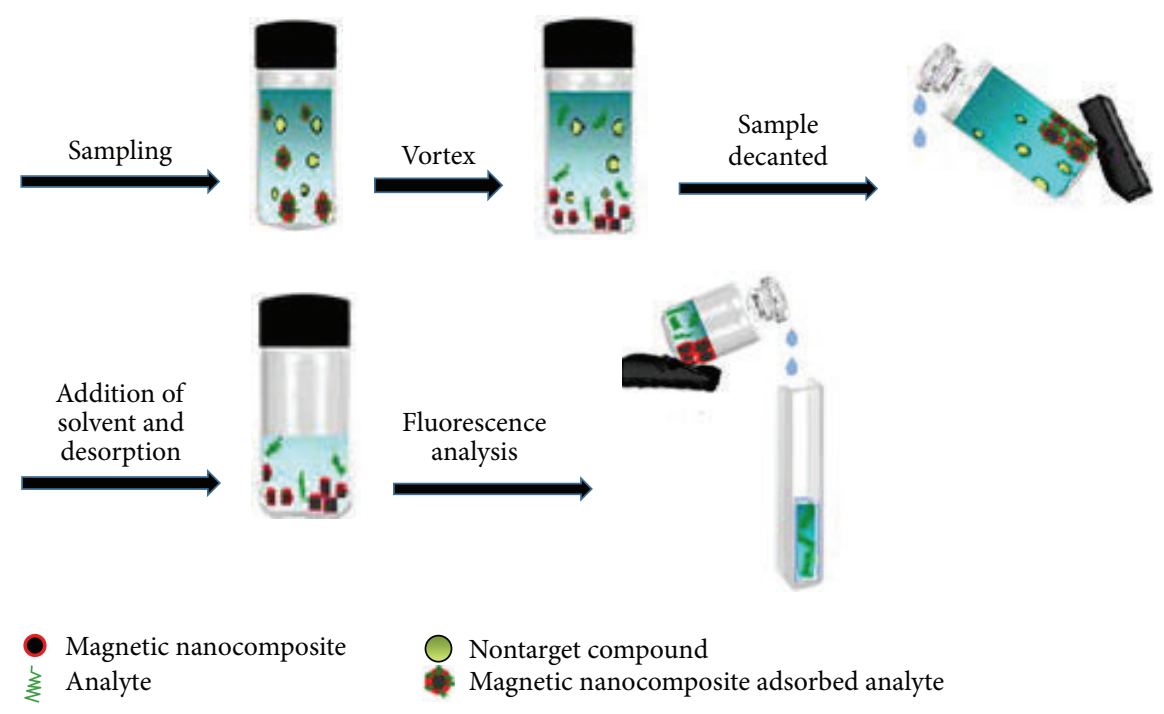

FIGURE 2: The whole extraction/desorption process setup.

of sodium hydroxide $(1.5 \mathrm{M})$ was added dropwise to the sodium hydroxide solution under maximum vigorous stirring in $30 \mathrm{~min}$ under an inert atmosphere of $\mathrm{N}_{2}$ gas. The hemimicelle of CS formed on the surface of magnetic nanoparticles and the solution color changed from orange to brown immediately. The resulting brown precipitates were separated from the previous medium using an external magnet. Finally, at room temperature, the suspension was washed sequentially with deionized water $(3 \times 100 \mathrm{~mL})$ and methanol $(3 \times 100 \mathrm{~mL})$ as well as ultrapure water $(5 \times 200 \mathrm{~mL})$.

2.4. Preparation of Polythiophene/Chitosan Magnetic Nanocomposite. The preparation procedure of polythiophene/chitosan magnetic nanocomposite consisted of the following steps. First, chitosan $/ \mathrm{Fe}_{3} \mathrm{O}_{4}$ submicrospheres containing functional groups (such as $-\mathrm{OH}$ and $-\mathrm{NH}_{2}$ groups) were prepared according to the above method. The hydrophobic and hydrophilic moieties of CS-MNPs could facilitate the dissolution of thiophene monomers. The next stage, the polythiophene/chitosan magnetic nanocomposite, was prepared by self-assembly polymerization method. Chitosan/magnetic nanoparticles $(0.5 \mathrm{~g})$ along with different amount of thiophene monomers were successively added into $25 \mathrm{~mL}$ of ultrapure water under maximum vigorous stirring in $30 \mathrm{~min}$ under an inert atmosphere of $\mathrm{N}_{2}$ gas at $60^{\circ} \mathrm{C}$. Then suitable amount of APS, as initiator, was added to the solution and stirred for $1 \mathrm{~h}$ at this temperature. At this stage, the solution color was immediately changed from brown to black and polythiophene/chitosan magnetic nanocomposites were obtained. At room temperature, the resulting polythiophene/chitosan magnetic nanocomposite was collected by external magnet and washed several times by redispersion in methanol and double distilled water until the filtrate became colorless.

2.5. Extraction Procedure. For the magnetic solid phase extraction, $25 \mathrm{mg}$ of polythiophene/chitosan magnetic nanocomposite was added into $50 \mathrm{~mL}$ double distillated water sample spiked with $1 \mathrm{mg} \mathrm{L}^{-1}$ of fluoxetine under the maximum stirring rate at room temperature for $10 \mathrm{~min}$. Then, by applying external magnet on the outer wall of the vial, the polythiophene/chitosan magnetic nanocomposite could be easily collected and supernatant was removed. For desorption of fluoxetine from these magnetic sorbents, they were immersed in $1.5 \mathrm{~mL}$ of methanol for $3 \mathrm{~min}$. Finally, the fluorescence spectrum of the desorbed solution was recorded by the spectrofluorimetric method. The extraction and desorption procedure was shown in Figure 2.

2.6. Real Sample Preparation. The human urine was obtained from the healthy volunteer and it is to be free of the selected drug. This urine sample was filtered using centrifugation at $10000 \mathrm{rpm}$ for $10 \mathrm{~min}$ and the supernatant was fully collected. Then, the certain amount of fluoxetine standard solution was added into the urine supernatant and diluted $(1: 10 \mathrm{v} / \mathrm{v})$ by double distillated water. Blank samples were prepared in the same way without the analyte-spiking step. Blood samples were obtained from a healthy individual and centrifuged at $10000 \mathrm{rpm}$. A plasma standard was prepared by adding the certain amount of fluoxetine standard solution to the diluted drug-free plasma solution to obtain the desired concentrations.

2.7. Instruments and Measurement. The EDAX analysis along with the scanning electronic microscopy (SEM) image was recorded by Cambridge Stereoscan 360 SEM Instrument (England) operating at $20 \mathrm{kV}$. Fourier transform infrared spectroscopy (FTIR) spectra were recorded using ABB Bomem MB100 (Quebec, Canada). Thermal stability of obtained sorbent was studied using thermogravimetric analysis (TGA): TG 209 F1 Iris-Thermogravimetric Analyzer from NETZSCH (Germany) at a heating rate of $20^{\circ} \mathrm{C} \mathrm{min}{ }^{-1}$ in the temperature range of $50-700^{\circ} \mathrm{C}$ under nitrogen atmosphere. The fluorescence spectra were registered by a Varian Cary Eclipse fluorescence spectrophotometer (Springvale, Victoria, Australia) equipped with $1 \mathrm{~cm} \times 1 \mathrm{~cm}$ quartz cell and 
a xenon lamp. The fluorescence scan mode with slit widths of $5 \mathrm{~nm}$ was used for spectra recordings under excitation and emission wavelengths of 246 and $311 \mathrm{~nm}$, respectively. The emission lines were recorded by A PMT detector at $600 \mathrm{~V}$. The $\mathrm{pH}$ of sample was determined using a Metrohm Herisan $\mathrm{pH}$ meter (Switzerland). A $1.4 \mathrm{~T}$ magnet of $\mathrm{NdFeB}$ with model N48 ( $80 \mathrm{~mm}, 40 \mathrm{~mm}$, and $30 \mathrm{~mm}$ ) was purchased from Ningbo Strong Magnet Material Co., Ltd. (Ningbo, China).

\section{Results and Discussion}

In this work, a magnetic solid phase extraction based on a new magnetic nanocomposite sorbent for isolation of fluoxetine in a single step has been successfully developed. To achieve the maximum extraction efficiency of fluoxetine, several parameters such as volume and type of desorption solvent, sorbent amount, sample $\mathrm{pH}$, adsorption, and desorption times and ionic strength of sample spiked with $1 \mathrm{mg} \mathrm{L}^{-1}$ of fluoxetine were optimized. Each experiment was performed in triplicate. To evaluate the influence of any factors, the peak intensity of extracted fluoxetine at $311 \mathrm{~nm}$ was considered.

\subsection{Characterization of Polythiophene/Chitosan Nanocompos-} ite. The CS on the surface of magnetic nanoparticles played a significant role in the polythiophene-chitosan magnetic nanocomposites formation. Therefore, alkaline precipitation of aqueous solutions containing Fe (II) and Fe (III) at the present CS was performed. By adding sodium hydroxide, sample $\mathrm{pH}$ is increased to above 6.5 and the surface of $\mathrm{Fe}_{3} \mathrm{O}_{4}$ nanoparticles becomes negative. The charge of mineral oxides is negative when the $\mathrm{pH}$ value is above isoelectric point; while when the $\mathrm{pH}$ value is below this point then the surface of mineral oxides is positively charged. These negative charges on $\mathrm{Fe}_{3} \mathrm{O}_{4}$ nanoparticles, due to electrostatic attraction force with positive charge of $-\mathrm{NH}_{2}$ and $-\mathrm{OH}$ group in $\mathrm{CS}$, could hold CS on the surface of them. Therefore, a complex of thiophene and CS-MNPs in aqueous solution was formed due to the acid-base and dipole-dipole interactions between -S group in thiophene monomers and the $-\mathrm{OH}$ and $-\mathrm{NH}_{2}$ group in CS. Finally, APS solution was added dropwise to the above solution and polymerization on the surface of the CS-MNPs takes place. Consequently, the "core" of CS-PTh magnetic nanocomposite is $\mathrm{Fe}_{3} \mathrm{O}_{4}$ nanoparticles while the "shell" of the prepared composite is CS-PTh (Figure 3).

The FTIR spectra of MNPs, CS-MNP, and polythiophenechitosan magnetic nanocomposite are shown in Figure 4 . The stretching vibration peak of $\mathrm{Fe}-\mathrm{O}$ at $570 \mathrm{~cm}^{-1}$ was observed in all the curves which confirmed the presence of $\mathrm{Fe}_{3} \mathrm{O}_{4}$ NPs in all synthesized materials. Moreover, in the spectrum of CS-MNPs was observed the characteristic absorption bands for CS at 2855 and $2927 \mathrm{~cm}^{-1}$ (C-H stretching vibrations), $3472 \mathrm{~cm}^{-1}$ (O-H and $\mathrm{N}-\mathrm{H}$ stretching vibrations), and $1104 \mathrm{~cm}^{-1}$ (C-O-C stretching vibrations) along with one additional band at $570 \mathrm{~cm}^{-1}$ that corresponds to $\mathrm{Fe}-\mathrm{O}$. The FTIR spectrum of the polythiophene-chitosan magnetic nanocomposite was containing the $\mathrm{Fe}-\mathrm{O}$ stretching vibration peak at $570 \mathrm{~cm}^{-1}$ related to MNP and the other characteristic absorption peaks of PTh such as band at $690 \mathrm{~cm}^{-1}$ for C-S stretching and the peaks at 2855 and $2927 \mathrm{~cm}^{-1}$ for the C-H stretching vibrations as well as peaks at 1546 and $1402 \mathrm{~cm}^{-1}$ that belong to $\mathrm{C}-\mathrm{C}$ asymmetric and symmetric stretching vibrations of thiophene ring. Also, a peak observed in $1188 \mathrm{~cm}^{-1}$ is related to in-plane $\mathrm{C}-\mathrm{H}$ aromatic bending vibrations of thiophene ring. All these proved that polythiophenechitosan was coated on the surface of $\mathrm{Fe}_{3} \mathrm{O}_{4}$ NPs.

The TGA data of polythophene-chitosan magnetic nanocomposite in the range of $50-700^{\circ} \mathrm{C}$ was obtained under inert atmosphere of nitrogen. The TGA curve indicated a small initial weight loss under $160^{\circ} \mathrm{C}$ due to desorption of adsorbed water from the sample surface, followed by a continuous weight loss of the polythiophene-chitosan polymer coating layer that occurred above $160^{\circ} \mathrm{C}$ until $700^{\circ} \mathrm{C}$ due to decomposition of it (Figure 5). According to the weight loss, the amount of polythiophene-CS coating on $\mathrm{Fe}_{3} \mathrm{O}_{4} \mathrm{NPs}$ was estimated to be approximately $5.8 \%$.

The morphology and structure of magnetic nanoparticles, chitosan magnetic and polythiophene/chitosan magnetic nanocomposite, were determined by SEM and FTIR. The SEM image of the dispersed iron oxide nanoparticles along with histogram plot shows that the synthesized MNPs have rather high surface area and the size of nanoparticles is less than $50 \mathrm{~nm}$ (Figures 6(a) and 6(b)). In this work, the synthesized $\mathrm{Fe}_{3} \mathrm{O}_{4}$ /chitosan and polythiophene/chitosan magnetic nanocomposite (Figures 6(c) and 6(d)) have large specific surface area and are more suitable for absorption application. Figure 6(c) shows that the final products exhibit slight aggregation as a result of surface modification by the attachment of PTh. This could be attributed to the fact that the reaction might occur on the particle surface and several PTh molecules were bound to chitosan on the magnetic particle.

The EDXA spectrum of polythiophene-chitosan magnetic nanocomposite is also shown in Figure 7. The spectrum of polythiophene-chitosan magnetic nanocomposite indicates that the molar ratio of carbon, oxygen, sulfur, and iron are $47.36 \%, 26.92 \%, 12.65 \%$, and $4.25 \%$, respectively. It demonstrates that polythiophene was successfully coated on the chitosan $/ \mathrm{Fe}_{3} \mathrm{O}_{4}$ nanoparticles.

3.2. Selection of Eluting Solvent. The desorption solvent is an important parameter that has to optimized in the MSPE procedure. A minimum volume of suitable solvent can effectively desorb the analyte with less interfering impurities. In this experiment, six solvents, that is, ethanol, methanol, acetonitrile, dichloromethane, $\mathrm{n}$-hexane, and acetone, were studied. The polar solvents such as acetonitrile, methanol, and ethanol provided good results (Figure 8(a)). However, there was maximum peak intensity when using methanol as eluting solvent. Therefore, methanol was selected. The solvent volume and desorption time were investigated. The volume of solvent increased from 0.5 to $2 \mathrm{~mL}(0.5 \mathrm{~mL}$ every time), and the desorption time from 0.5 to 10 min under maximum stirring rate was studied (Figure 9(c)). The time of desorption should be as short as possible while carryover effects must be considered comprehensively. The result indicated that desorption could occur completely within $3 \mathrm{~min}$ and $1.5 \mathrm{~mL}$ of methanol without carryover effect. 


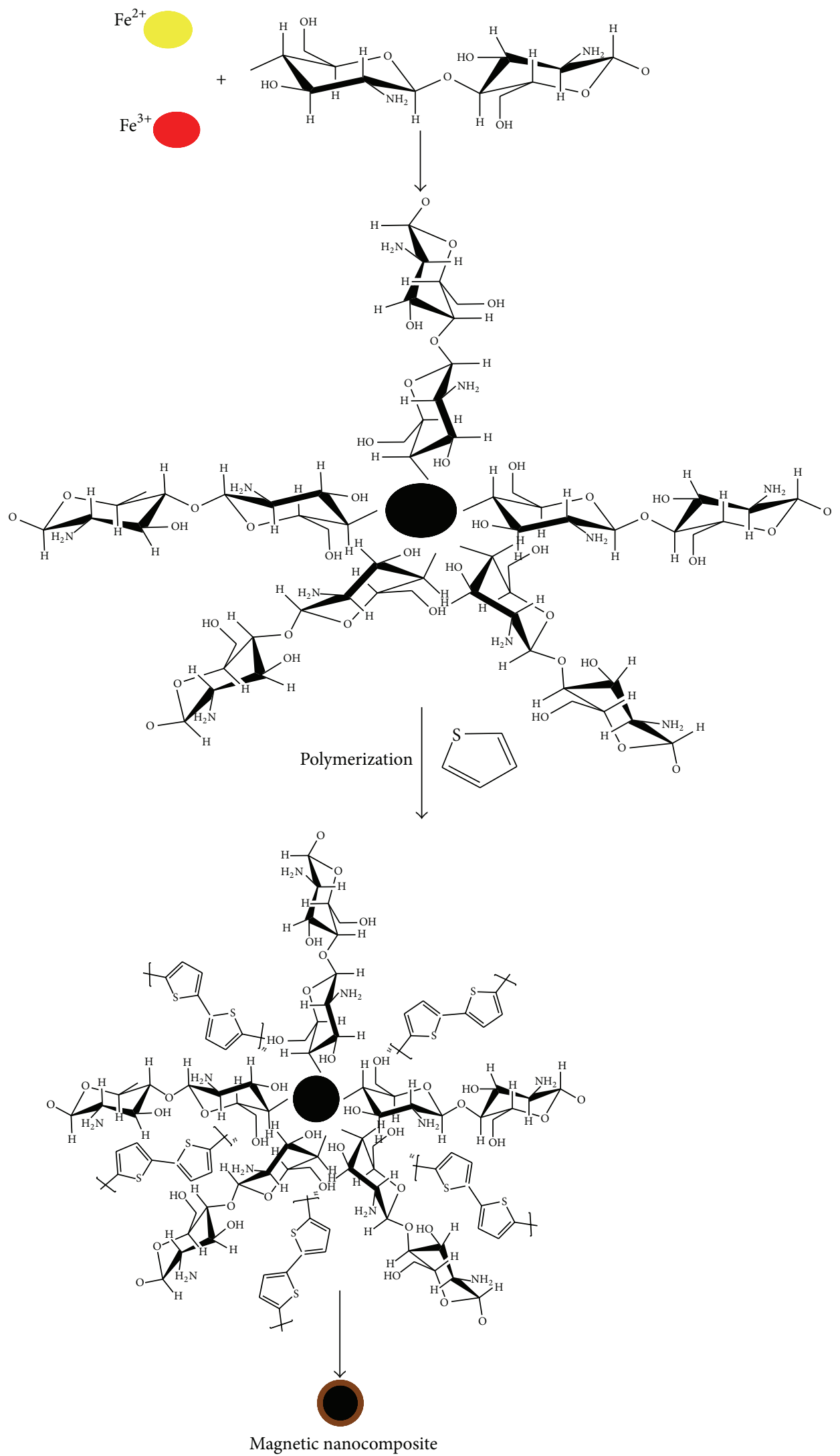

FIGURE 3: Schematic diagram for the preparation of CS-PTh magnetic nanocomposite. 


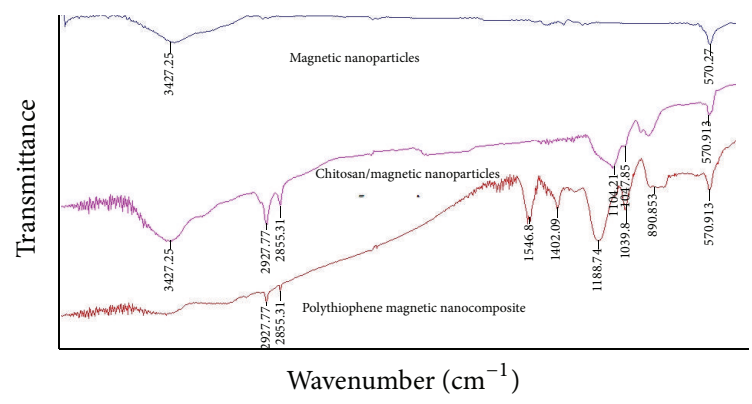

FIGURE 4: FTIR spectra of MNPs, CS-MNPs, and polythiophene-CS magnetic nanocomposite.

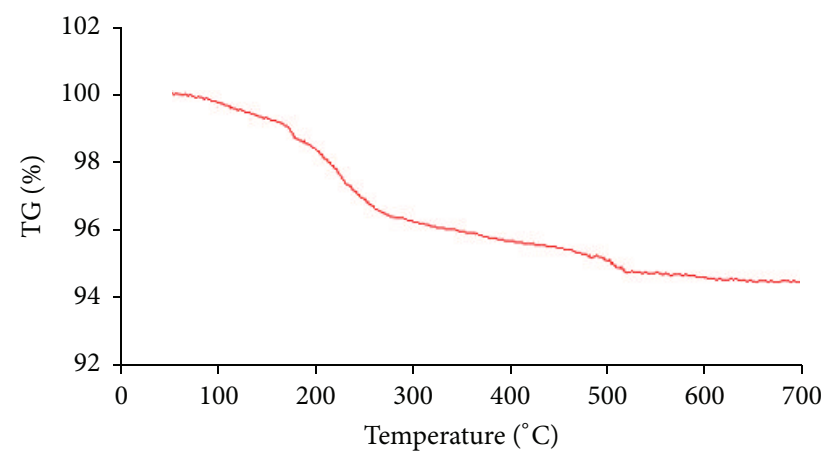

FIGURE 5: The data of TGA analyses for polythiophene-chitosan magnetic nanocomposite.

3.3. Sample $p H$. An influencing factor at the adsorption of polar compounds is solution $\mathrm{pH}$ that affects the charge of species and density on the sorbents surface. The effect of sample $\mathrm{pH}$ was considered from 1 to 11 . The experimental results (Figure 8(b)) showed that the polythiophene/chitosan magnetic nanocomposite gave the best performance in neutral solution $(\mathrm{pH}=7)$. This result can be easily described via the electrostatic forces between functional group of fluoxetine $(-\mathrm{NH})$ and functional groups in polythiophene-chitosan magnetic nanocomposite $\left(-\mathrm{NH}_{2}\right.$ and $-\mathrm{OH}$ at chitosan along with $-\mathrm{S}$ at thiophene) in the solutions having different $\mathrm{pH}$ values. Therefore, extraction efficiency of magnetic sorbent was probably reduced because the surface of the adsorbent (sulfur, oxygen, and nitrogen donor atoms) and fluoxetine (nitrogen donor atom) was protonated in strong acidic solutions. At this region $(\mathrm{pH}<5)$ both of the analyte and sorbent have the same charge; an electrostatic repulsion force between them is expected to lower the extraction efficiency. As can be seen from the related figure further increase of $\mathrm{pH}$ above 7 resulted in slight decrease of extraction; thus, most likely $\mathrm{pH} 7$ was selected because it provides the highest recoveries.

3.4. Ionic Strength. The ionic strength effect has been commonly used in various extraction techniques. Generally, addition of salt usually enhances the ionic strength of the aqueous solution and would affect the solubility of organic solutes. The increased ionic strength can reduce the concentration of water molecules available to dissolve solute molecules causing solutes to move faster into extracting medium. Therefore, the influence of ionic strength was considered in the range of 0 $30 \%(\mathrm{w} / \mathrm{v})$ of $\mathrm{NaCl}$ (Figure $8(\mathrm{c})$ ). The effect of salting out was used in solid phase extraction and liquid-liquid extraction methods. However, the addition of salt had an adverse effect on the extraction efficiency of the magnetic solid phase extraction. This phenomena may occur due to the reduction of active sites on the magnetic sorbent or due to the increase in viscosity of the aqueous sample that is impeding the masstransfer process. Consequently, the salt addition into water samples was abandoned.

3.5. Effect of the Amount of Magnetic Nanocomposite. The nanoadsorbents compared to microadsorbents have more satisfactory results because of their greater surface areas. To find the optimized amount of adsorbent, the amounts of $\mathrm{PTh} / \mathrm{CS}$ magnetic nanocomposite were investigated from 2 to $100 \mathrm{mg}$. The results show that only $25 \mathrm{mg}$ of magnetic sorbent was required to obtain maximum extraction of fluoxetine under the same conditions. When the amount was over $25 \mathrm{mg}$, all the PTh/CS magnetic nanocomposite may not effectively collect in the same time, which leads to a reduction in extraction efficiency. Furthermore, the minor amount of magnetic PTh/CS magnetic nanocomposite justifies the minimal volumes of elution solvent for efficient release of the analyte from the sorbent. Therefore, $25 \mathrm{mg}$ of new sorbent was used in the next experiments, which was much less than the literature-reported amount of the commonly used microadsorbents.

3.6. The Effect of Components Ratio. The structure and morphology of adsorbent are crucial parameters in the extraction approach. In this work, the extraction efficiency of $\mathrm{Fe}_{3} \mathrm{O}_{4}$ nanoparticles coated with CS and different type of PTh/CS in various components ratios and undecorated magnetic nanoparticles were investigated by extracting fluoxetine, a model compound, from water samples. According to Figure 9(a) the extraction capabilities of the CS-MNPs are also higher than the undecorated iron oxide nanoparticles. Also, the effect of the thiophene concentration was considered in the range of $0.3-2 \mathrm{M}$, while CS-MNPs amount constantly remained at level of $0.5 \mathrm{~g}$. The obtained results indicated that, by increasing the thiophene concentration until $0.9 \mathrm{M}$, the peak intensity was enhanced. Therefore, this trend conforms that PTh has an important effect in the extraction process and this concentration was chosen as the optimum value. By increasing the thiophene content in reaction solution, the magnetic properties of polythiophene/chitosan magnetic nanocomposite were decreasing and can lead to the loss of sorbent during their collection by the external magnetic field.

3.7. Effect of Extraction Time on the Adsorption Efficiency. The extraction time in the range of 1-20 min for the isolation of fluoxetine from water samples was studied (Figure 9(b)). The results of this experiment showed that the adsorption equilibrium time was achieved at about $10 \mathrm{~min}$. The high surface area of MNPs along with uniform disperse of the sorbent throughout the sample could be the promising reasons for attaining such a fast extraction process. This is a superior benefit over the conventional SPE and other microextraction 


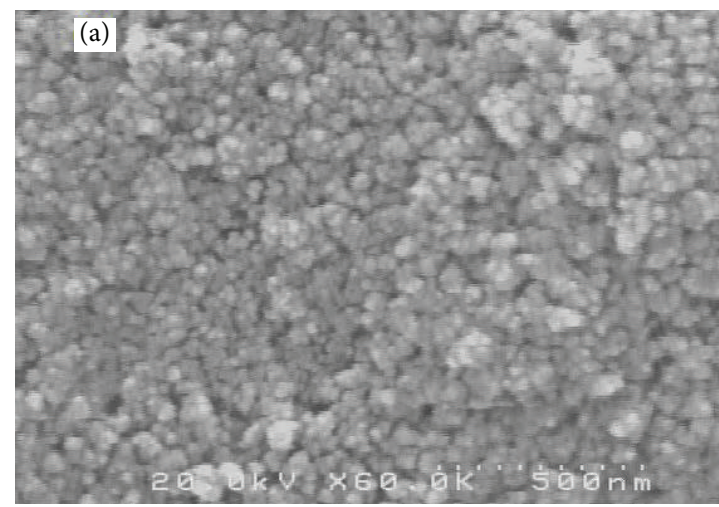

(b)
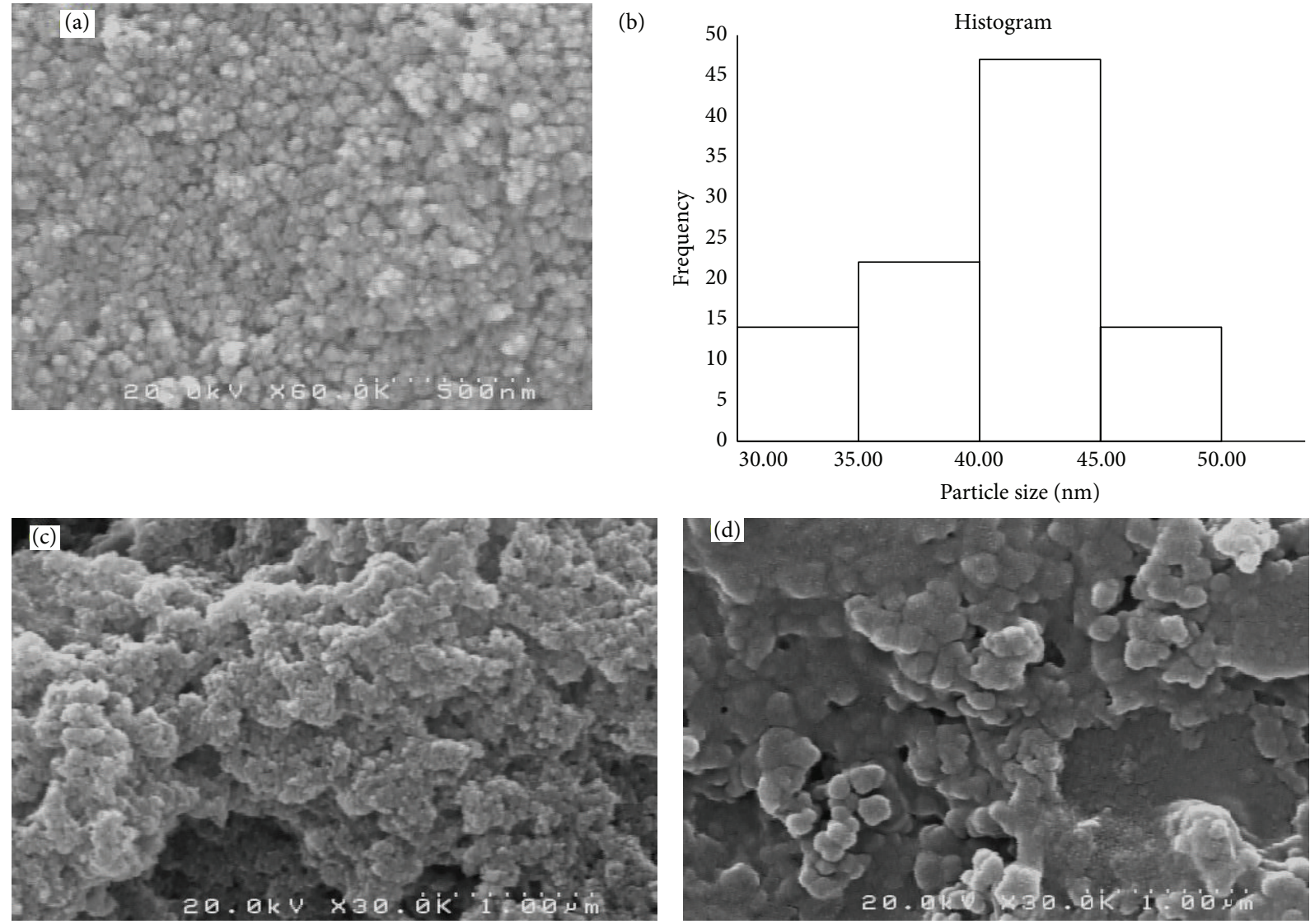

FIGURE 6: SEM images of magnetic nanoparticles (a), the histogram of nanoparticles based on the SEM image analysis of 100 particles (b), chitosan $/ \mathrm{Fe}_{3} \mathrm{O}_{4}$ (c), and polythiophene-chitosan magnetic nanocomposite (d).

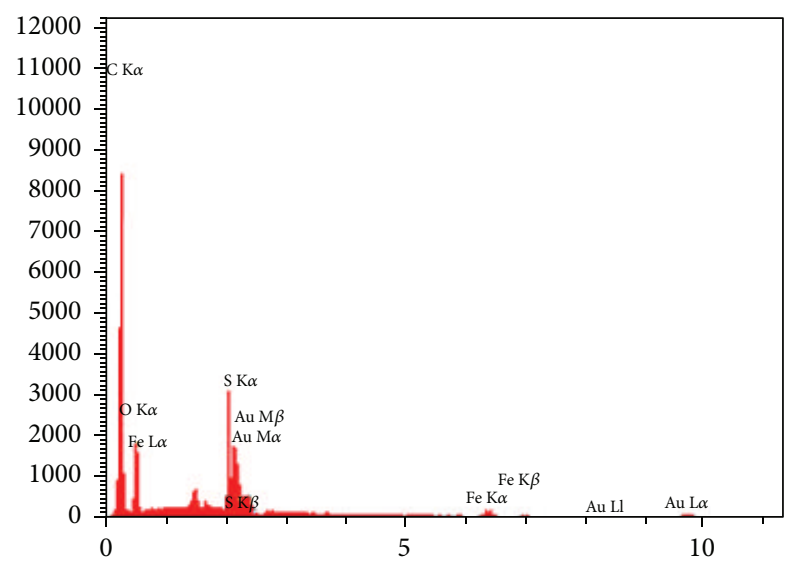

$(\mathrm{keV})$

\begin{tabular}{lccccc}
\hline Elt & Line & Int & Error & W\% & A\% \\
\hline $\mathrm{C}$ & $\mathrm{Ka}$ & 1012.8 & 168.2314 & 47.36 & 54.07 \\
$\mathrm{O}$ & $\mathrm{Ka}$ & 296.3 & 38.3234 & 26.93 & 29.44 \\
$\mathrm{~S}$ & $\mathrm{Ka}$ & 207.4 & 27.4432 & 12.65 & 9.11 \\
$\mathrm{Fe}$ & $\mathrm{Ka}$ & 26.3 & 0.5471 & 4.25 & 1.31 \\
$\mathrm{Au}$ & $\mathrm{Ka}$ & 10.1 & 0.6388 & 8.82 & 6.07 \\
& & & & 100.00 & 100.00 \\
\hline
\end{tabular}

FIGURE 7: The EDAX spectrum of polythiophene-chitosan magnetic nanocomposite. techniques, which generally need more than $30-60 \mathrm{~min}$ to touch the equilibrium. Consequently, an extraction time of 10 min was selected for the subsequent experiment.

3.8. Sorbent Reusability. Reusability is a considerable factor for estimating the efficiency of a magnetic sorbent. For determination of reusability, the extraction of the fluoxetine with the magnetic sorbent was performed for 25 times at the same condition. The obtained results indicated that the polythiophene-chitosan magnetic nanocomposite can be applied at least 25 times without a major loss of the extraction efficiency, while extraction efficiency after 30 times observed loss of $3 \%$. Also, the reusability of the chitosan magnetic nanoparticles was considered and the result revealed that its extraction efficiency after 5 times extraction was reduced $>14 \%$. It shows that polythiophene induces a good stability to the CS-MNP. Also, stability of solvent is frequently associated with MSPE when it is coupled with derivatization techniques and/or liquid chromatography. Therefore, it is needed to immerse the polythiophene-chitosan magnetic nanocomposite directly into the appropriate solvent for $2 \mathrm{~h}$. Solvent stability of the polythiophene-chitosan magnetic nanocomposite was considered to ensure that the synthesized coating has no bleeding during its contact with the organic solvent. The effect of several solvents with different polarities including water, dichloromethane, methanol, and acetonitrile was therefore 


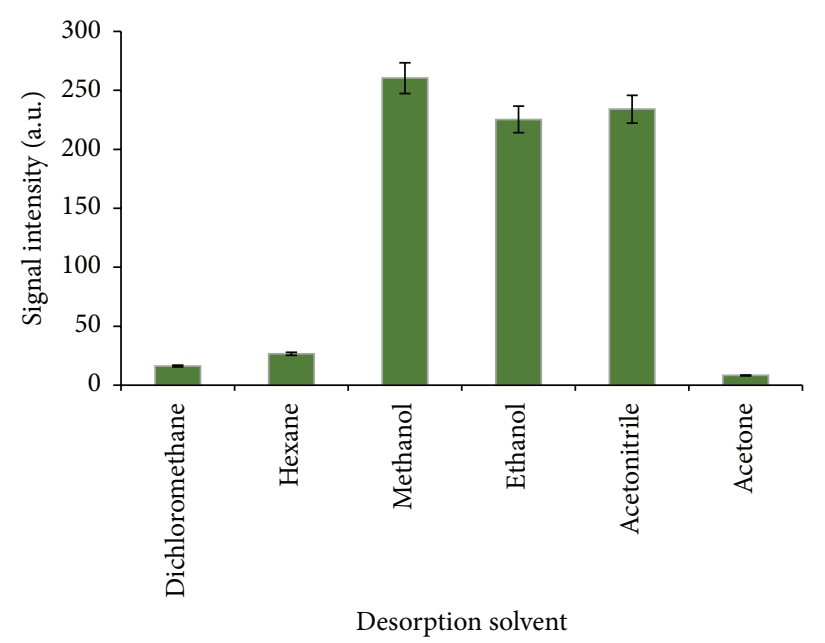

(a)

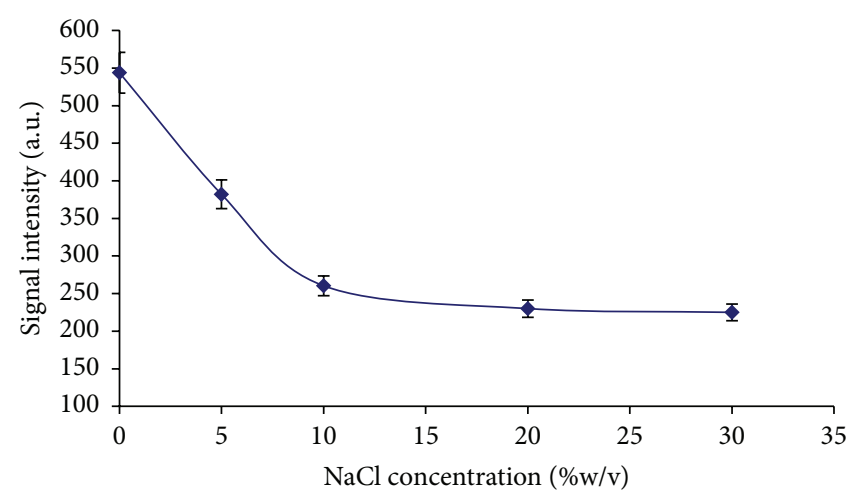

(c)

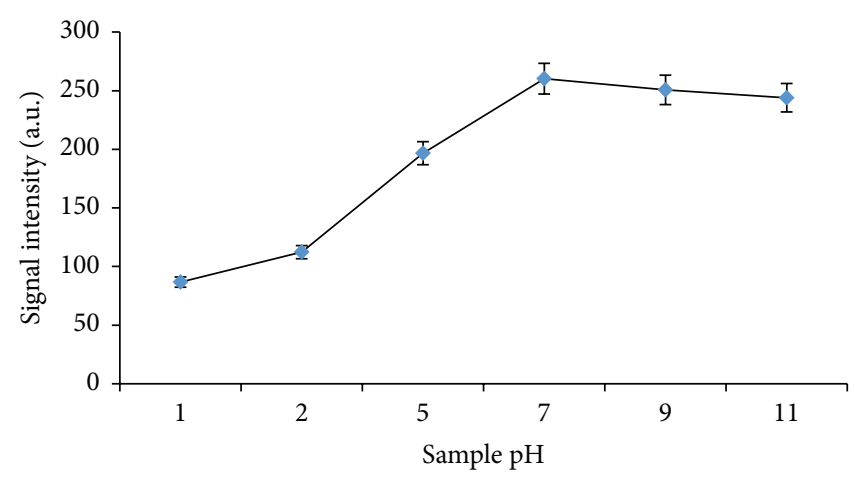

(b)

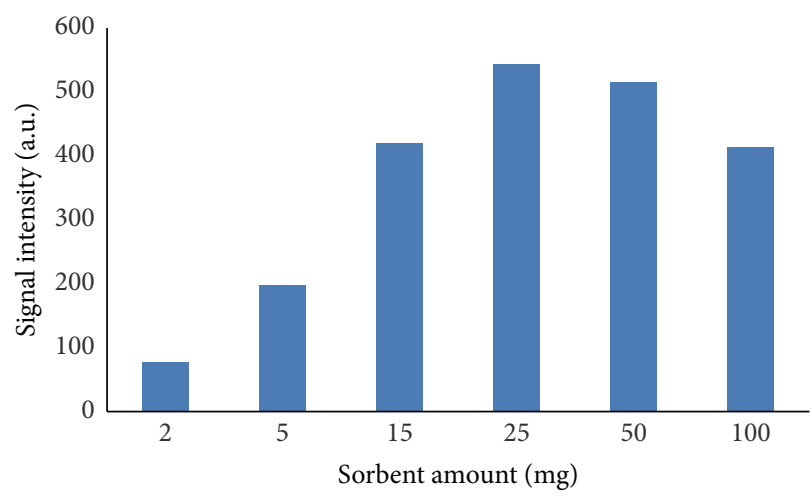

(d)

FIGURE 8: Effects of desorption solvent (a), ionic strength (b), sample $\mathrm{pH}(\mathrm{c})$, and sorbent amount (d) on the extraction efficiency.

TABLE 1: Relative recoveries obtained for fluoxetine in different real samples.

\begin{tabular}{lcccc}
\hline Sample & $\begin{array}{c}\text { Fluoxetine } \\
\text { added } \\
\left(\mu \mathrm{g} \mathrm{L}^{-1}\right)\end{array}$ & $\begin{array}{c}\text { Fluoxetine } \\
\text { found } \\
\left(\mu \mathrm{g} \mathrm{L}^{-1}\right)\end{array}$ & Recovery $(\%)$ & $\begin{array}{c}\text { RSD\% } \\
(n=3)\end{array}$ \\
\hline Tap water & 0 & 0 & - & - \\
\hline Urine & 75 & 70 & 93 & 2 \\
\hline $\begin{array}{l}\text { Blood } \\
\text { plasma }\end{array}$ & 0 & 0 & - & - \\
\hline
\end{tabular}

considered. Two hours after sinking, extraction efficiency of polythiophene-chitosan magnetic nanocomposite at optimized condition was constant.

3.9. Analytical Performance. After the optimization of important factors of magnetic solid phase extraction technique based on PTh/CS magnetic nanocomposite, some analytical features such as linear dynamic range, correlation of determination, limit of detection (LOD), limit of quantification
(LOQ), and repeatability or relative standard deviation (RSD) were investigated. Analytical performance of the developed procedure is plotted in Table 1. Calibration curve via plotting peak intensity of each concentration versus associated concentrations of the fluoxetine in the range of $0.015-1 \mathrm{mg} \mathrm{L}^{-1}$ was obtained. The developed method exhibits a good linearity for fluoxetine throughout the concentration range with determination coefficient of $R^{2}=0.9994$. The LOD $(\mathrm{S} / \mathrm{N}=3)$ and LOQ $(\mathrm{S} / \mathrm{N}=10)$ values were 5 and $15 \mu \mathrm{g} \mathrm{L}^{-1}$, respectively. The RSD value for five independent sample preparations was $2 \%$ at a concentration level of $75 \mu \mathrm{g} \mathrm{L}^{-1}$. The reliability of current method was considered in various real samples such as tap water, human plasma, and human urine samples. The results in Table 1 confirm the validity of the proposed method. The fluorescence spectrum of extracted fluoxetine from urine sample spiked at $75 \mu \mathrm{g} \mathrm{L}^{-1}$ is shown in Figure 10. The current work compared with several other methods on the determination of fluoxetine (Table 2) and the results indicated that it is either comparable or has rather pronounced advantages. Also, the results shown that the MSPE method based on new magnetic sorbent is a sensitive, easy, efficient, and reliable along with good analytical parameters in isolation of the fluoxetine from biological and aqueous samples. 
TABLE 2: Comparing the current work with some other methods used for the determination of fluoxetine.

\begin{tabular}{|c|c|c|c|c|c|c|c|}
\hline Method & Recovery (\%) & $\mathrm{LOD}^{\mathrm{a}}\left(\mu \mathrm{g} \mathrm{L}^{-1}\right)$ & $\mathrm{LDR}^{\mathrm{b}}\left(\mu \mathrm{g} \mathrm{L}^{-1}\right)$ & $\operatorname{RSD}^{\mathrm{c}}(\%)$ & Analytical grade $\%$ & Triplicate & Ref. \\
\hline Spectrofluorimetry & 97 & 70 & $250-5000$ & 2.2 & 99 purity & $n=5$ & [43] \\
\hline LLE-CPE-FL & 102 & 100 & $5000-50000$ & 3.5 & 99 purity & $n=5$ & [43] \\
\hline Spectrophotometry & 19 & - & $1000-2000$ & 1.0 & 99 purity & $n=5$ & {$[10]$} \\
\hline SBSE-LC-MS & $52-63$ & 3 & $10-500$ & 5.0 & Analytical standards & $n=5$ & {$[8]$} \\
\hline LLE-HPLC-FL & $97-99$ & - & $25-1000$ & 1.0 & 99 purity & $n=5$ & {$[2]$} \\
\hline SPE-CZE & 89 & 10 & $100-200$ & 3.0 & - & $n=7$ & {$[5]$} \\
\hline Magnetic-SPE- SF & $80-104$ & 20 & $50-1000$ & 1.4 & $>99.3$ purity & - & [35] \\
\hline Magnetic-SPE- SF & $76-99$ & 1 & $50-5000$ & 3 & $>99.3$ purity & $n=3$ & [44] \\
\hline Fluorimetric method & $97-100$ & 11 & $35-500$ & 3 & 99.5 purity & $n=5$ & [45] \\
\hline Developed method & $56-93$ & 5 & $15-1000$ & 2 & & & - \\
\hline
\end{tabular}

${ }^{a}$ Limit of detection.

${ }^{\mathrm{b}}$ Linear dynamic range.

${ }^{c}$ Relative standard deviation.

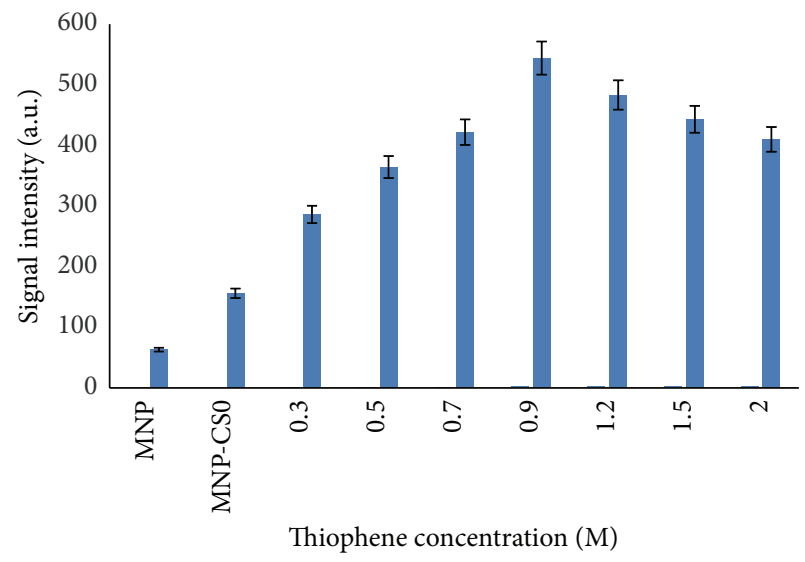

(a)

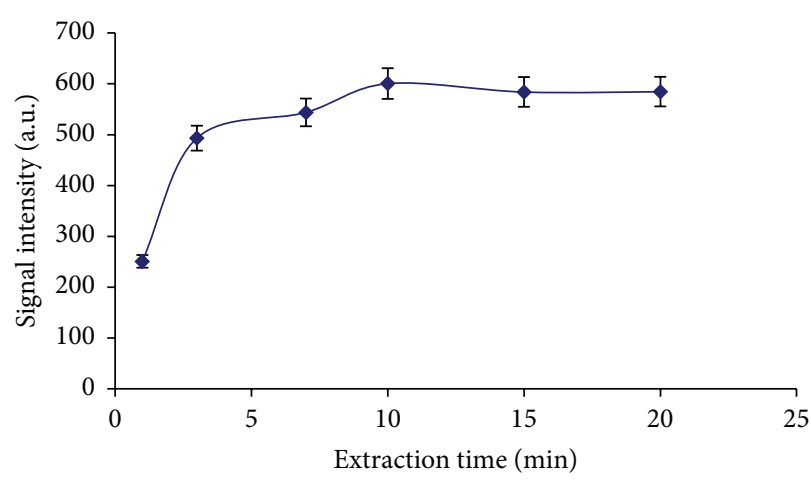

(b)

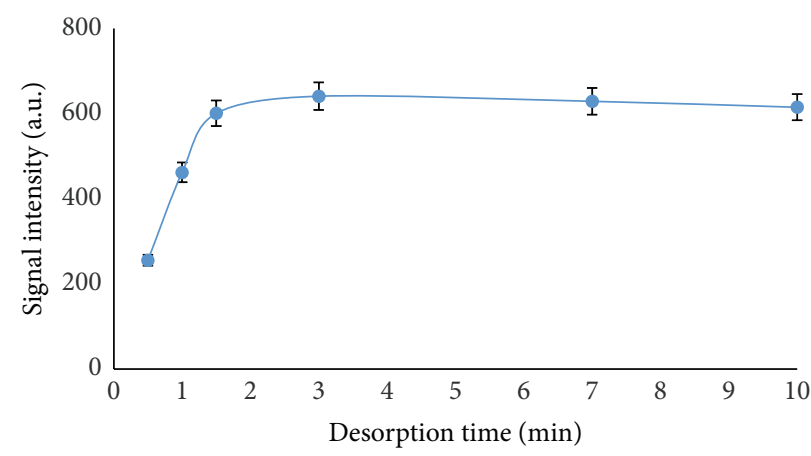

(c)

FIGURE 9: Effect of nanocomposite components ratio (a), extraction time (b), and desorption time (c) on the extraction efficiency.

Furthermore, fast and cost-effective synthesis of the polythiophene/chitosan magnetic nanocomposite along with fewer amounts of sorbent and organic solvent as well as high stability in different solution is the vital advantage of the current method in comparison with other reports.

\section{Conclusions}

A novel type of modified magnetic nanoparticles coated with polythiophene was synthesized and employed as magnetic solid phase extraction adsorbent for isolation of fluoxetine in biological and aqueous water. Polythiophene/CS magnetic nanocomposite could be easily produced in large quantity using the oxidized polymerization method. The separation of fluoxetine-loaded magnetic adsorbent from the solution could be easily achieved via an external magnetic field. Moreover, the optimal method had attained acceptable analysis results of biological sample with a little amount of adsorbents within a short time. Coating of MNPs with polythiophene can not only increase adsorption ability of the target analyte, 


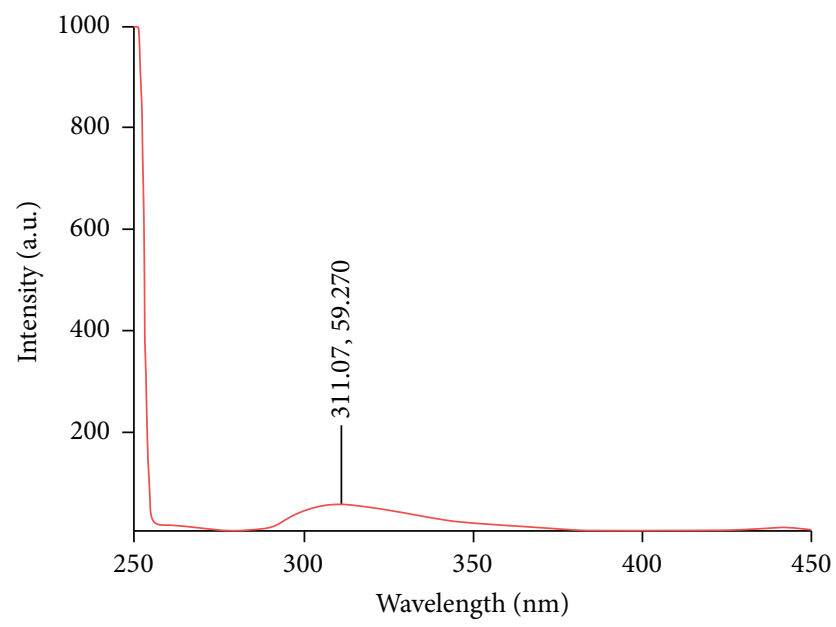

FIGURE 10: Fluorescence spectra of fluoxetine extracted from human urine sample with spiking fluoxetine at $75 \mu \mathrm{g} \mathrm{L}^{-1}$.

due to the existence of new interactions (hydrophobic and $\pi-\pi$ interactions) between sorbent and target analyte, but also improve stability of the MNPs and their dispersibility in aqueous media.

\section{Competing Interests}

The authors declare that they have no competing interests.

\section{References}

[1] "Fluoxetine hydrochloride capsules and tablets," Eli Lilly and Company Material Safety Data Sheet, Eli Lilly and Company, Indianapolis, Ind, USA, 2004.

[2] M. A. Raggi, F. Bugamelli, G. Casamenti, R. Mandrioli, D. De Ronchi, and V. Volterra, "Analytical methods for the quality control of Prozac ${ }^{\circledast}$ capsules," Journal of Pharmaceutical and Biomedical Analysis, vol. 18, no. 4-5, pp. 699-706, 1998.

[3] R. F. Suckow, M. F. Zhang, and T. B. Cooper, "Sensitive and selective liquid-chromatographic assay of fluoxetine and norfluoxetine in plasma with fluorescence detection after precolumn derivatization," Clinical Chemistry, vol. 38, no. 9, pp. 1756-1761, 1992.

[4] N. Unceta, A. Gómez-Caballero, A. Sánchez et al., "Simultaneous determination of citalopram, fluoxetine and their main metabolites in human urine samples by solid-phase microextraction coupled with high-performance liquid chromatography," Journal of Pharmaceutical and Biomedical Analysis, vol. 46, no. 4, pp. 763-770, 2008.

[5] J. R. Flores, J. J. B. Nevado, G. C. Peñalvo, and N. M. Diez, "Development and validation method for determination of fluoxetine and its main metabolite norfluoxetine by nonaqueous capillary electrophoresis in human urine," Talanta, vol. 65, no. 1, pp. 163-171, 2005.

[6] M. A. Raggi, R. Mandrioli, G. Casamenti, V. Volterra, C. Desiderio, and S. Fanali, "Improved HPLC determination of flouxetine and norflouxetine in human plasma," Chromatographia, vol. 50, no. 7-8, pp. 423-427, 1999.
[7] A. L. Saber, "On-line solid phase extraction coupled to capillary LC-ESI-MS for determination of fluoxetine in human blood plasma," Talanta, vol. 78, no. 1, pp. 295-299, 2009.

[8] C. Fernandes, P. Jiayu, P. Sandra, and F. M. Lanças, "Stir bar sorptive extraction-LC-MS for the analysis of fluoxetine in plasma," Chromatographia, vol. 64, no. 9-10, pp. 517-521, 2006.

[9] S. M. R. Wille, K. E. Maudens, C. H. Van Peteghem, and W. E. E. Lambert, "Development of a solid phase extraction for 13 'new' generation antidepressants and their active metabolites for gas chromatographic-mass spectrometric analysis," Journal of Chromatography A, vol. 1098, no. 1-2, pp. 19-29, 2005.

[10] A. H. Prabhakar, V. B. Patel, and R. Giridhar, "Spectrophotometric determination of fluoxetine hydrochloride in bulk and in pharmaceutical formulations," Journal of Pharmaceutical and Biomedical Analysis, vol. 20, no. 3, pp. 427-432, 1999.

[11] J. Li, X. Zhao, Y. Shi, Y. Cai, Sh. Mou, and G. Jiang, "Mixed hemimicelles solid-phase extraction based on cetyltrimethylammonium bromide-coated nano-magnets $\mathrm{Fe}_{3} \mathrm{O}_{4}$ for the determination of chlorophenols in environmental water samples coupled with liquid chromatography/spectrophotometry detection," Journal of Chromatography A, vol. 1180, no. 1-2, pp. 24-31, 2008.

[12] L. Yang, P. Su, X. Chen, R. Zhang, and Y. Yang, "Microwaveassisted synthesis of poly(ionic liquid)-coated magnetic nanoparticles for the extraction of sulfonylurea herbicides from soil for HPLC," Analytical Methods, vol. 7, no. 7, pp. 3246-3252, 2015.

[13] L. Bai, B. Mei, Q.-Z. Guo, Z.-G. Shi, and Y.-Q. Feng, "Magnetic solid-phase extraction of hydrophobic analytes in environmental samples by a surface hydrophilic carbon-ferromagnetic nanocomposite," Journal of Chromatography A, vol. 1217, no. 47, pp. 7331-7336, 2010.

[14] X. Batlle and A. Labarta, "Finite-size effects in fine particles: magnetic and transport properties," Journal of Physics D: Applied Physics, vol. 35, no. 6, pp. R15-R42, 2002.

[15] S. X. Zhang, H. Y. Niu, Y. Q. Cai, and Y. L. Shi, "Barium alginate caged $\mathrm{Fe}_{3} \mathrm{O}_{4} @ \mathrm{C}_{18}$ magnetic nanoparticles for the preconcentration of polycyclic aromatic hydrocarbons and phthalate esters from environmental water samples," Analytica Chimica Acta, vol. 665, no. 2, pp. 167-175, 2010.

[16] U. Jeong, X. W. Teng, Y. Wang, H. Yang, and Y. Xia, "Superparamagnetic colloids: controlled synthesis and niche applications," Advanced Materials, vol. 19, no. 1, pp. 33-60, 2007.

[17] C.-C. Hsu and C.-W. Whang, "Microscale solid phase extraction of glyphosate and aminomethylphosphonic acid in water and guava fruit extract using alumina-coated iron oxide nanoparticles followed by capillary electrophoresis and electrochemiluminescence detection," Journal of Chromatography A, vol. 1216, no. 49, pp. 8575-8580, 2009.

[18] Q. Gao, D. Luo, J. Ding, and Y.-Q. Feng, "Rapid magnetic solidphase extraction based on magnetite/silica/poly(methacrylic acid-co-ethylene glycol dimethacrylate) composite microspheres for the determination of sulfonamide in milk samples," Journal of Chromatography A, vol. 1217, no. 35, pp. 5602-5609, 2010.

[19] J. S. Beveridge, J. R. Stephens, A. H. Latham, and M. E. Williams, "Differential magnetic catch and release: analysis and separation of magnetic nanoparticles," Analytical Chemistry, vol. 81, no. 23, pp. 9618-9624, 2009.

[20] M. R. Habibi and M. Ghasemi, "Numerical study of magnetic nanoparticles concentration in biofluid (blood) under influence of high gradient magnetic field," Journal of Magnetism and Magnetic Materials, vol. 323, no. 1, pp. 32-38, 2011. 
[21] P. I. Girginova, A. L. Daniel-da-Silva, C. B. Lopes et al., "Silica coated magnetite particles for magnetic removal of $\mathrm{Hg}^{2+}$ from water," Journal of Colloid and Interface Science, vol. 345, no. 2, pp. 234-240, 2010.

[22] Y. Lu, Y. D. Yin, B. T. Mayers, and Y. N. Xia, "Modifying the surface properties of superparamagnetic iron oxide nanoparticles through a sol-gel approach," Nano Letters, vol. 2, no. 3, pp. 183-186, 2002.

[23] Z. B. Li, D. N. Huang, C. F. Fu et al., "Preparation of magnetic core mesoporous shell microspheres with C18-modified interior pore-walls for fast extraction and analysis of phthalates in water samples," Journal of Chromatography A, vol. 1218, no. 37, pp. 6232-6239, 2011.

[24] X. L. Zhang, H. Y. Niu, Y. Y. Pan, Y. L. Shi, and Y. Q. Cai, "Chitosan-coated octadecyl-functionalized magnetite nanoparticles: preparation and application in extraction of trace pollutants from environmental water samples," Analytical Chemistry, vol. 82, no. 6, pp. 2363-2371, 2010.

[25] I. P. Román, A. Chisvert, and A. Canals, "Dispersive solid-phase extraction based on oleic acid-coated magnetic nanoparticles followed by gas chromatography-mass spectrometry for UVfilter determination in water samples," Journal of Chromatography A, vol. 1218, no. 18, pp. 2467-2475, 2011.

[26] X. Y. Liu, J. J. Yin, L. Zhu, G. H. Zhao, and H. X. Zhang, "Evaluation of a magnetic polysulfone microcapsule containing organic modified montmorillonite as a novel solid-phase extraction sorbent with chlorophenols as model compounds," Talanta, vol. 85, no. 5, pp. 2451-2457, 2011.

[27] Z. Xu, J. Zhang, L. Cong et al., "Preparation and characterization of magnetic chitosan microsphere sorbent for separation and determination of environmental estrogens through SPE coupled with HPLC," Journal of Separation Science, vol. 34, no. 1, pp. 46-52, 2011.

[28] J. R. Meng, C. Y. Shi, B. W. Wei, W. J. Yu, C. H. Deng, and X. M. Zhang, "Preparation of $\mathrm{Fe}_{3} \mathrm{O}_{4} @ \mathrm{C} @ P A N I$ magnetic microspheres for the extraction and analysis of phenolic compounds in water samples by gas chromatography-mass spectrometry," Journal of Chromatography A, vol. 1218, no. 20, pp. 2841-2847, 2011.

[29] J. R. Meng, J. Bu, C. H. Deng, and X. M. Zhang, "Preparation of polypyrrole-coated magnetic particles for micro solid-phase extraction of phthalates in water by gas chromatography-mass spectrometry analysis," Journal of Chromatography A, vol. 1218, no. 12, pp. 1585-1591, 2011.

[30] G. Zhao, S. Song, C. Wang, Q. Wu, and Z. Wang, "Determination of triazine herbicides in environmental water samples by high-performance liquid chromatography using graphenecoated magnetic nanoparticles as adsorbent," Analytica Chimica Acta, vol. 708, no. 1-2, pp. 155-159, 2011.

[31] Y.-B. Luo, Z.-G. Shi, Q. Gao, and Y.-Q. Feng, "Magnetic retrieval of graphene: extraction of sulfonamide antibiotics from environmental water samples," Journal of Chromatography A, vol. 1218, no. 10, pp. 1353-1358, 2011.

[32] Q. H. Wu, G. Y. Zhao, C. Feng, C. Wang, and Z. Wang, "Preparation of a graphene-based magnetic nanocomposite for the extraction of carbamate pesticides from environmental water samples," Journal of Chromatography A, vol. 1218, no. 44, pp. 7936-7942, 2011.

[33] D. Pardasani, P. K. Kanaujia, A. K. Purohit, A. R. Shrivastava, and D. K. Dubey, "Magnetic multi-walled carbon nanotubes assisted dispersive solid phase extraction of nerve agents and their markers from muddy water," Talanta, vol. 86, no. 1, pp. 248-255, 2011.

[34] Y. Moliner-Martínez, A. Ribera, E. Coronado, and P. CampínsFalcó, "Preconcentration of emerging contaminants in environmental water samples by using silica supported $\mathrm{Fe}_{3} \mathrm{O}_{4}$ magnetic nanoparticles for improving mass detection in capillary liquid chromatography," Journal of Chromatography A, vol. 1218, no. 16, pp. 2276-2283, 2011.

[35] H. Bagheri, O. Zandi, and A. Aghakhani, "Extraction of fluoxetine from aquatic and urine samples using sodium dodecyl sulfate-coated iron oxide magnetic nanoparticles followed by spectrofluorimetric determination," Analytica Chimica Acta, vol. 692, no. 1-2, pp. 80-84, 2011.

[36] H. Eskandari and M. R. Shariati, "Dodecylbenzene sulfonatecoated magnetite nanoparticles as a new adsorbent for solid phase extraction-spectrophotometric determination of ultra trace amounts of ammonium in water samples," Analytica Chimica Acta, vol. 704, no. 1-2, pp. 146-153, 2011.

[37] M. M. Abolghasemi and V. Yousefi, "Polythiophene/hexagonally ordered silica nanocomposite coating as a solid-phase microextraction fiber for the determination of polycyclic aromatic hydrocarbons in water," Journal of Separation Science, vol. 37, no. 1-2, pp. 120-126, 2014.

[38] B. Buszewski, P. Olszowy, S. Pikus, and M. Kozak, "Electropolymerized nanoporous polymeric SPME coatings: preparation and characterization by small angle X-ray scattering and scanning electron microscopy," Chemical Monthly, vol. 145, no. 3, pp. 527-531, 2014.

[39] X. Li, C. Li, J. Chen, C. Li, and C. Sun, "Polythiophene as a novel fiber coating for solid-phase microextraction," Journal of Chromatography A, vol. 1198-1199, no. 1-2, pp. 7-13, 2008.

[40] E. Tahmasebi, Y. Yamini, M. Moradi, and A. Esrafili, "Polythiophene-coated $\mathrm{Fe}_{3} \mathrm{O}_{4}$ superparamagnetic nanocomposite: synthesis and application as a new sorbent for solid-phase extraction," Analytica Chimica Acta, vol. 770, pp. 68-74, 2013.

[41] E. Tahmasebi and Y. Yamini, "Polythiophene-coated $\mathrm{Fe}_{3} \mathrm{O}_{4}$ nanoparticles as a selective adsorbent for magnetic solid-phase extraction of silver(I), gold(III), copper(II) and palladium(II)," Microchimica Acta, vol. 181, no. 5-6, pp. 543-551, 2014.

[42] C. $\mathrm{Hu}, \mathrm{Z}$. Mou, G. Lu et al., "3D graphene- $\mathrm{Fe}_{3} \mathrm{O}_{4}$ nanocomposites with high-performance microwave absorption," Physical Chemistry Chemical Physics, vol. 15, no. 31, pp. 13038-13043, 2013.

[43] R. Mandrioli, V. Pucci, D. Visini, G. Varani, and M. A. Raggi, "Rapid methods for determination of fluoxetine in pharmaceutical formulations," Journal of Pharmaceutical and Biomedical Analysis, vol. 29, no. 6, pp. 1127-1134, 2002.

[44] H. Bagheri, A. Roostaie, and R. Daliri, "An electrospun magnetic nanocomposite for a facile micro-scaled analysis approach," Analytical Methods, vol. 6, no. 15, pp. 5838-5846, 2014.

[45] I. A. Darwish, S. M. Amer, H. H. Abdine, and L. I. Al-Rayes, "New spectrophotometric and fluorimetric methods for determination of fluoxetine in pharmaceutical formulations," International Journal of Analytical Chemistry, vol. 2009, Article ID 257306, 9 pages, 2009.

[46] X. Zhao, Y. Shi, Y. Cai, and S. Mou, "Cetyltrimethylammonium bromide-coated magnetic nanoparticles for the preconcentration of phenolic compounds from environmental water samples," Environmental Science and Technology, vol. 42, no. 4, pp. 1201-1206, 2008. 

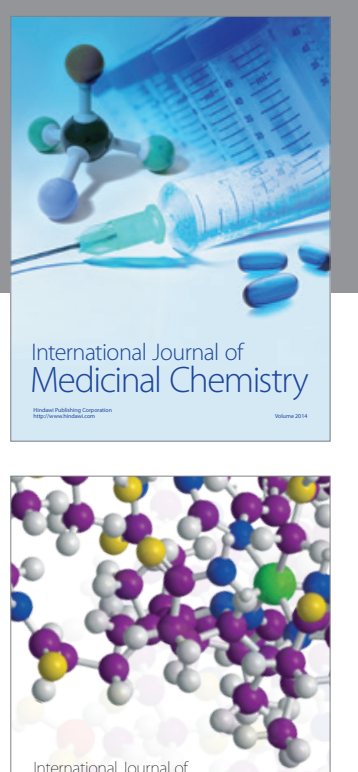

Carbohydrate Chemistry

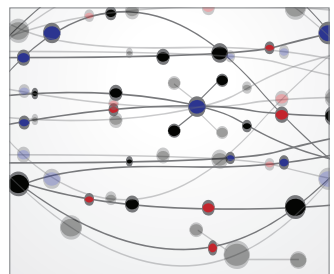

The Scientific World Journal
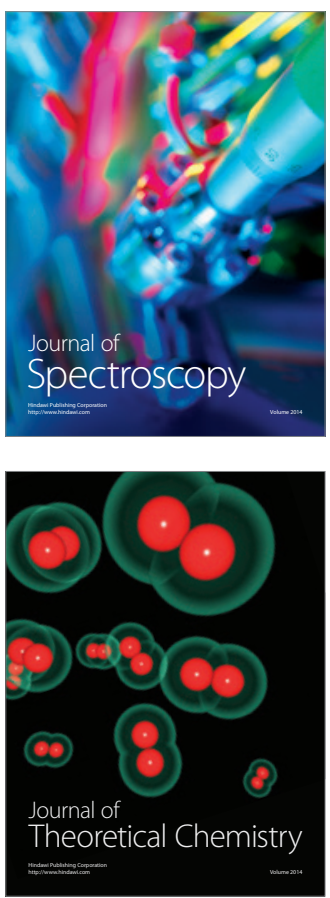
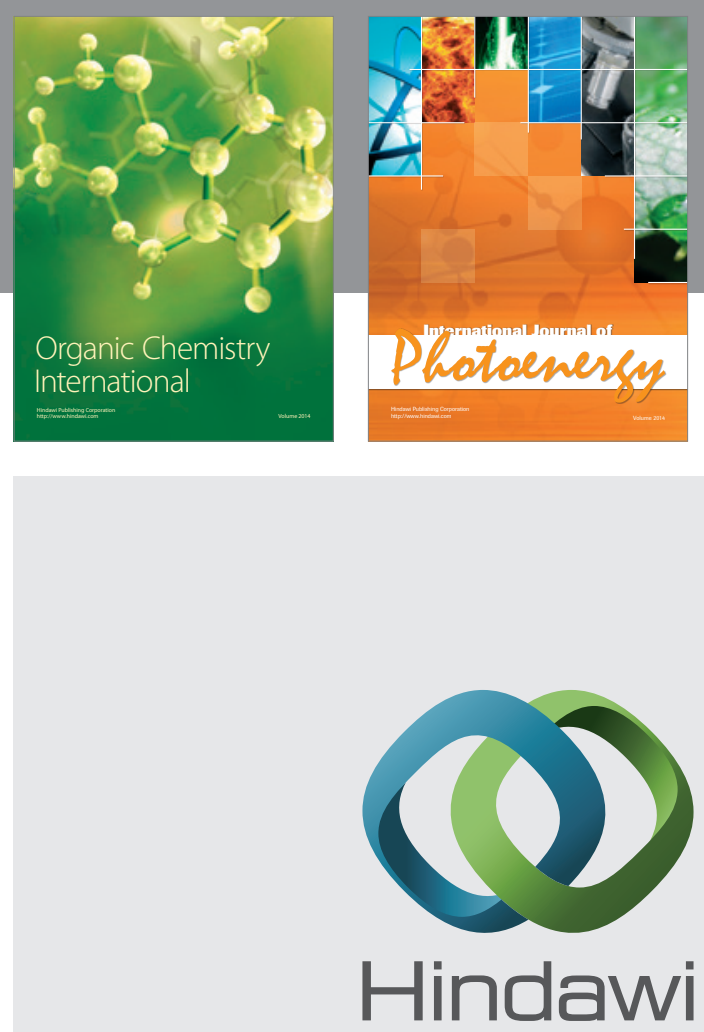

Submit your manuscripts at

http://www.hindawi.com

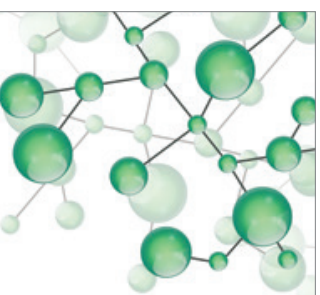

International Journal of

Inorganic Chemistry

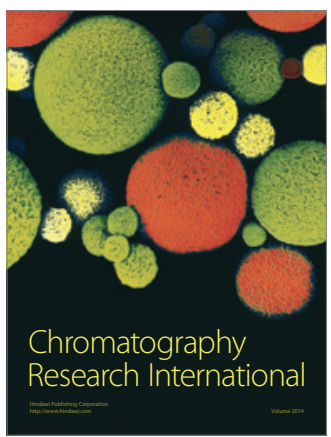

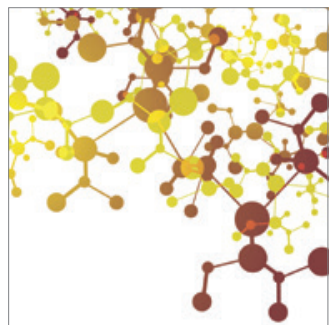

Applied Chemistry
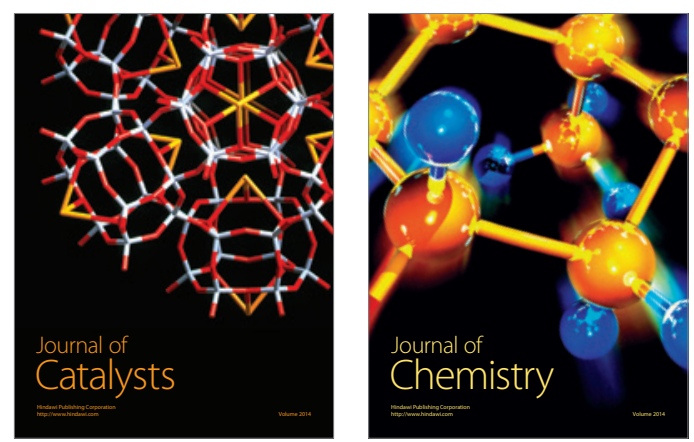
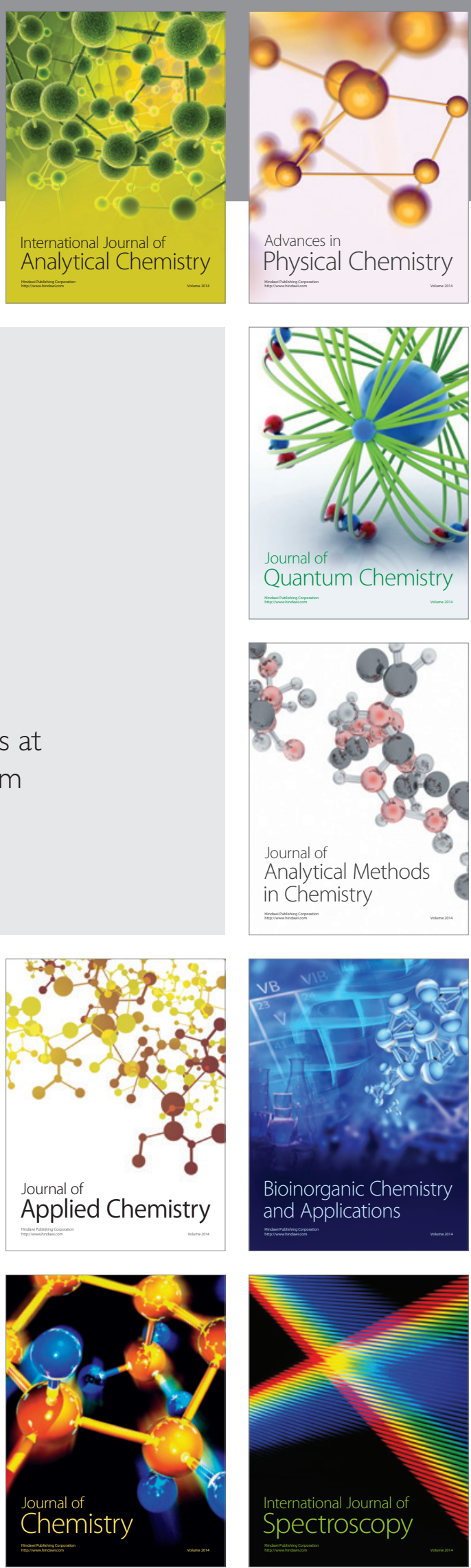